\title{
Prof. Dr. F. E. Zanella-A Training and Development Mentor in Neuroradiology
}

\author{
H. Lanfermann ${ }^{1} \cdot$ R. D. de Rochemont ${ }^{2} \cdot$ J. Berkefeld $^{2}$
}

Published online: 3 November 2017

(c) Springer-Verlag GmbH Germany 2017

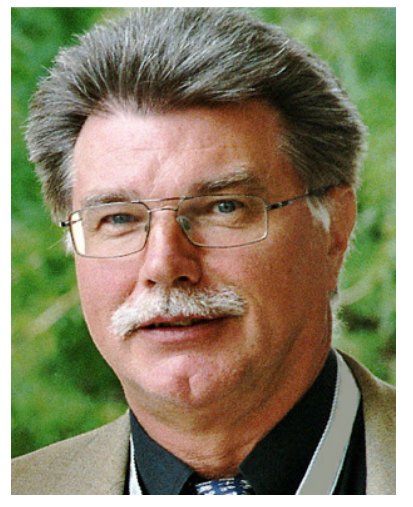

Prof. Dr. F. E. Zanella

Professor Friedhelm Zanella studied medicine in Cologne. He subsequently completed his training (which he had begun in 1979) under Professor Gerd Friedmann as a medical specialist in radiology at Cologne University Hospital. There he specialized in neuroradiology, a subdiscipline that at the time was not recognized as a field in which one could specialize and not necessarily regarded as a good career move for someone seeking to get ahead in the field of radiology. At an early stage he developed extensive expertise in the rapidly growing field of neuroradiological magnetic resonance imaging (MRI) diagnostics and in 1989 gained his postdoctoral lecturing qualification (habilitation) on the subject of "The role of magnetic resonance imag-

H. Lanfermann

Lanfermann.Heinrich@mh-hannover.de

1 Institute for Diagnostic and Interventional Neuroradiology, Hannover Medical School, Hannover, Germany

2 Institute of Neuroradiology, Center of Radiology, University Hospital Frankfurt, Frankfurt, Germany ing in spinal and spinal canal diagnostics". He already had a very clear idea of how neuroradiology, if it was to become a subspecialty characterized by excellence in both the national and international arenas, should be structured as a discipline in its own right within university healthcare provision and research, as well as in higher education. Friedhelm Zanella therefore turned down the position of senior physician integrated into radiological services, heading the neuroradiological team in Cologne. Instead, he moved to the Department of Neuroradiology at the University Hospital Eppendorf (UKE) in Hamburg under Professor Hermann Zeumer. His goal was, alongside cross-sectional imaging diagnostics, to use the emerging interventional procedures, such as carotid artery stenting and aneurysm coiling, and to firmly establish them within this discipline. To raise the profile of neuroradiology as a field, he recognized the need to impart this valuable knowledge to active and aspiring neuroradiologists alike, at in-service training events, which held appeal for this target group. Thus, as long ago as 1991 he and Hermann Zeumer established the symposium "Neuroradiologie Aktuell" (Current Neuroradiology), which to this day remains highly successful as an event at national level.

In May 1992, he was appointed to a C3 university professorship in neuroradiology at UKE in Hamburg and 3 years later he accepted another $\mathrm{C} 3$ professorship in the same field at Essen University Hospital. Here, too, he was actively involved with in-service training. He initiated Germany's first basic course in neuroradiology (Basiskurs Neuroradiologie), focusing on the fundamentals of the discipline. In September 1996 he was appointed to succeed Professor Hans Hacker as C3 Professor of Neuroradiology at the J.W. Goethe University Frankfurt. A separate institute already existed here, which he was able to transform and develop further as he saw fit. Here in Frankfurt, and in close 


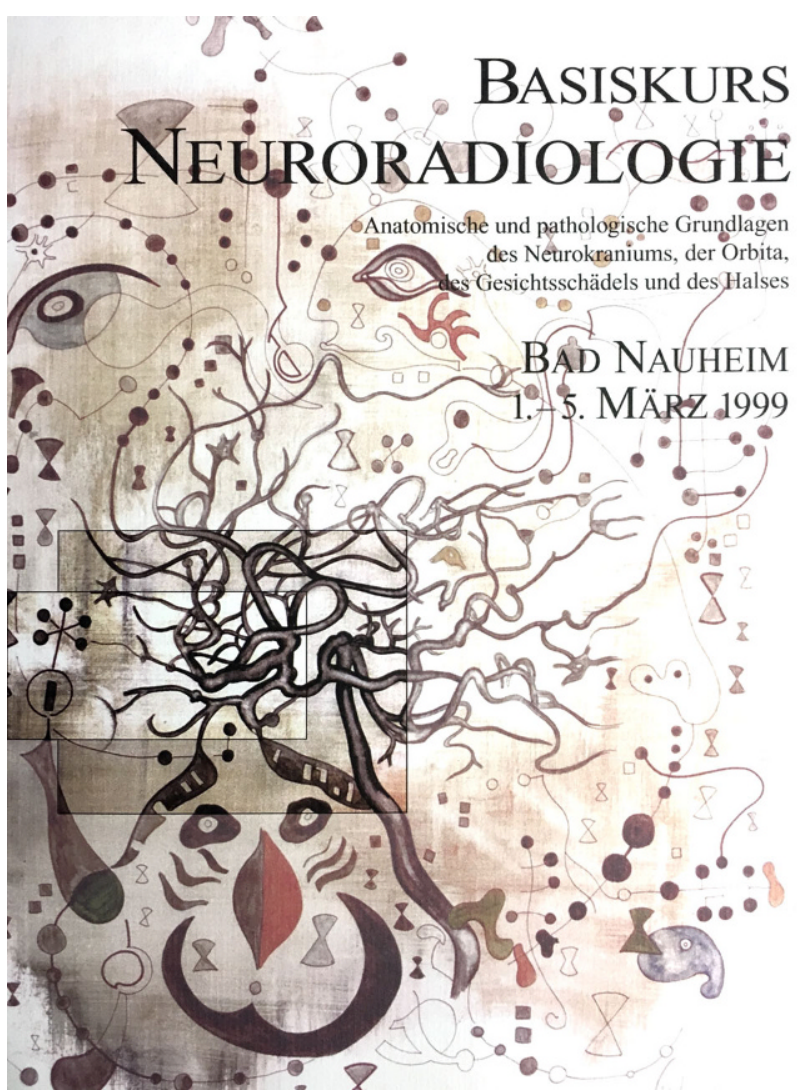

Fig. 1 Front page of the program for the 'Basiskurs Neuroradiologie' from 1999. (We are grateful to neuroradiologist Dr. Miro Orszagh for artwork entitled Hommage à Miró, and for permission to reproduce it)

collaboration with the clinical neurological specialties, he established a facility for both cross-sectional imaging diagnostics and internationally competitive MRI research that satisfied the requirements of a full service university hospital. At the same time, work began on establishing a setup for interventional neuroradiology, and the neurovascular research group, in an effectively structured manner.

After this intensive setting-up phase, Professor Zanella continued with his basic course in neuroradiology (Fig. 1). This became a leading in-service training event covering the basics of neuroradiology and head and neck radiology, with up to 49 contributors from Germany and elsewhere, guest speakers from the USA, and a tight program of lectures over a 5-day period. The response was excellent, and the event soon put Frankfurt on the map as a second focal point for in-service training, alongside Hamburg. The basic course in neuroradiology was continually being tailored to participants' needs and, having now being held 19 times, remains one of the most thematically broad neuroradiological in-service training offerings in the German-speaking world.

In cooperation with Professor Marco Essig and the Bender group, he also developed an in-service training opportunity with varying thematic emphases, called the Frankfurt
Neuroimaging Days ("Frankfurter Neuroimaging-Tage"). At a regional level, talks by high-profile speakers under the heading Neuroradiological Forum Frankfurt ("Neuroradiologische Forum Frankfurt", NFF) are also extremely popular.

In an international context, Professor Zanella was especially active on behalf of the European Society of Neuroradiology (ESNR). The 37th ESNR annual meeting, held in Frankfurt am Main under his presidency, was an outstanding success. He was consistently supported in these activities by his team of co-workers. In addition, he was awarded the Felix Wachsmann Prize by the German Radiological Society (DRG) for his accomplishments with regard to inservice training and professional development in radiology.

Friedhelm Zanella also made a significant contribution to scientific advancement in this field. He initiated and supported enduring interdisciplinary scientific projects. The Brain Imaging Center (BIC) in Frankfurt is a nationally visible facility. In 2004, in cooperation with the Departments of Neurology and Psychiatry, as well as the Max Planck Institute for Brain Research he built, with funding from the German Research Foundation (DFG), the German Federal Ministry for Education and Research (BMBF) and the federal state of Hesse, an interdisciplinary research center for neuroscientific imaging.

His activities aimed at boosting the careers of young scientists through "NeuroWiss e. V." are also high-profile on a nationwide basis; this is an organization for the advancement of neurological science, of which he has been deputy chair for many years now. He is also a long-time delegate of the German Society of Neuroradiology (DGNR) within the Association of the Scientific Medical Societies in Germany (AWMF). A further indication of his success in promoting his adopted science is the filling of $\mathrm{W} 3$ professorial posts in neuroradiology at both Hannover and Bonn, as well as the fact that co-workers at his institute have been honored with the Kurt Decker Award on several occasions. At an in-house level, quality management-related activities are particularly worthy of mention. For example, with the assistance of Ms Meike Stahmer, he achieved certification for his institute to the ISO standard in 2003. Among his strengths was to always regard the organization of the institute's work as a team effort and to encourage co-workers to develop themselves and to specialize, creatively and in their own way. In discussions, dedicated physicians and medical imaging technologists could always count on being treated on an equal footing and in discharging the primary roles of an institute director, he was also able to tap into the teammindedness he cultivated by drawing on the network of personal friendships that he maintained. His friendly contacts with representatives of related disciplines, and with clinical managers, were instrumental in strengthening neuromedicine and in fostering team spirit within the Neuro- 
center; however, a mere list of these achievements would not remotely do justice to the person Friedhelm Zanella. If we are to paint a more rounded picture of him, we have to mention that he was also an active sports enthusiast. Everyone who knows him is well aware that he imbued these leisure activities with the very same keenness with which he organized and invariably hosted with assuredness and kindness his in-service training conferences. After success as a handball player in the regional league, he was a tennis player of long standing and is now an enthusiastic golfer. The golf tournaments that he helped organize in connection with radiology conferences in Wiesbaden were especially popular; he also arranged highly memorable golf trips to South Africa, the homeland of his lovely wife Maliga.

Friedhelm, we are grateful for your admirable commitment to the advancement of neuroradiology, and we wish you and your wife all the very best for the future.

To express their appreciation, the nine articles following this laudation [1-9] in this edition of the journal are dedicated to you from your admirers in Frankfurt, Bonn and Hannover.

\section{References}

1. Berkefeld J, Wagner M, du Mesnil R. Carotid stenting in neuroradiology : a short journey from the past to current debates. Clin Neuroradiol. 2017 Jun 16. https://doi.org/10.1007/s00062-017-0603-y.

2. Weidauer S, Wagner M, Nichtweiß M. Magnetic resonance imaging and clinical features in acute and subacute myelopathies. Clin Neuroradiol. 2017 Jun 30. https://doi.org/10.1007/s00062-017-0604-x.
3. Ava L, Berkefeld J, Lauer A, Seiler A, Pfeilschifter W, Müller-Eschner M, You SJ, Weidauer S, Pilatus U, Wagner M. Predictive value of pooled cerebral blood volume mapping for final infarct volume in patients with major artery occlusions. A retrospective analysis. Clin Neuroradiol. 2017 Mar 13. https://doi.org/10.1007/ s00062-017-0569-9.

4. Tritt S, Ommer B, Gehrisch S, Klein S, Seifert V, Berkefeld J, Konczalla J. Optimization of the surgical approach in AVMs using MRI and 4D DSA fusion technique. Clin Neuroradiol. 2017 Mar 13. https://doi.org/10.1007/s00062-017-0571-2.

5. Kammerer S, Mueller-Eschner M, Berkefeld J, Tritt S. Time-resolved 3D rotational angiography (4D DSA) of the lenticulostriate arteries: display of normal anatomic variants and collaterals in cases with chronic obstruction of the MCA. Clin Neuroradiol. 2017 Mar 28. https://doi.org/10.1007/s00062-017-0578-8.

6. Müller A, Jurcoane A, Mädler B, Ditter P, Schild H, Hattingen E. Brain relaxometry after macrocyclic Gd-based contrast agent. Clin Neuroradiol. 2017 Jul 24. https://doi.org/10.1007/s00062-0170608-6.

7. Raab P, Sedlacek L, Buchholz S, Stolle S, Lanfermann H. Imaging Patterns of Rhino-Orbital-Cerebral Mucormycosis in Immunocompromised Patients : When to Suspect Complicated Mucormycosis. Clin Neuroradiol. 2017 Oct 12. https://doi.org/10.1007/s00062017-0629-1.

8. Raab P, Stangel M, Lanfermann H. Contribution of QSM imaging to the diagnosis of the rare syndrome of leukoencephalopathy with cysts and calcification (LCC). Clin Neuroradiol. 2017 May 5. https://doi.org/10.1007/s00062-017-0586-8.

9. Hattingen E, Handke N, Cremer K, Hoffjan S, Kukuk GM. Clinical and imaging presentation of a patient with beta-propeller proteinassociated neurodegeneration, a rare and sporadic form of neurodegeneration with brain iron accumulation (NBIA). Clin Neuroradiol. 2017 Jun 22. https://doi.org/10.1007/s00062-017-0605-9. 